\title{
A juvenile idiopathic arthritis biobank at the Royal Children's Hospital, Melbourne, Australia J Ellis*1, S Macnee ${ }^{2}$, A-L Ponsonby¹, J Akikusa², R Allen² and J Munro²
}

Address: ${ }^{1}$ Murdoch Children's Research Institute, Melbourne, Victoria, Australia and ${ }^{2}$ Royal Children's Hospital, Melbourne, Victoria, Australia

* Corresponding author

from $15^{\text {th }}$ Paediatric Rheumatology European Society (PreS) Congress

London, UK. 14-17 September 2008

Published: 15 September 2008

Pediatric Rheumatology 2008, 6(SuppI I):P5 doi:I0.II86/I546-0096-6-SI-P5

This abstract is available from: http://www.ped-rheum.com/content/6/SI/P5

(C) 2008 Ellis et al; licensee BioMed Central Ltd.

\section{Background}

Juvenile idiopathic arthritis (JIA) is a complex disease determined by both genetic and environmental factors. Whilst prior research has provided preliminary evidence for some factors, most studies have been hindered by small sample sizes and low statistical power. It is clear that to successfully identify causal factors for complex diseases, large sample sizes and comprehensive approaches will be required. To this end, we have established the Victorian JIA Biobank (VJIAB), a collaborative effort between the Royal Children's Hospital (RCH) and the Murdoch Childrens Research Institute in Melbourne Australia. Our aim is to collect biospecimens and extensive clinical and environmental information on 1000 cases (incident and prevalent, attending RCH Paediatric Rheumatology Clinic) and 1000 controls (healthy children, matched to cases by age and sex, attending RCH for elective surgery).

\section{Materials and methods}

The VJIAB was initiated in January 2008. A peripheral blood sample is being collected from all participants, from which plasma and mononuclear cells are being banked. An extensive questionnaire that includes over 130 items is also being completed to capture information from both parent and child on such aspects as medical and family history, early life environment (for consideration of the hygiene hypothesis), and sun exposure (for consideration of the role of Vitamin D in the autoimmune process).

\section{Results and conclusion}

To date, we have recruited 24 cases and matching controls. There are also plans to extend VJIAB to capture cases Australia-wide through the newly established Australian Paediatric Rheumatology Research Network. 